\section{Canadian Association of Gastroenterology Educational Needs Assessment Report}

\author{
Alaa Rostom MD FRCPC MSc, Chair, CAG Education Affairs \\ Sandra Daniels MSc, CAG National Office
}

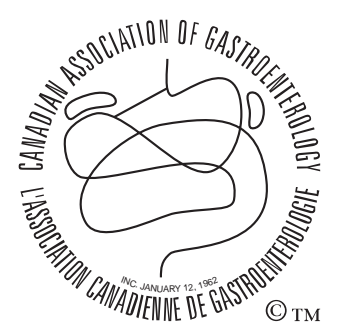

En français voir page 523
$\mathrm{T}_{\mathrm{c}}^{\mathrm{h}}$ he annual survey of the Canadian Association of Gastroenterology (CAG) members' educational needs was conducted via an online survey during March and April. Two hundred twenty-eight individuals completed the survey. Similar to previous years, inflammatory bowel disease (IBD) topics were most in demand for future educational events. Other highly rated areas included celiac disease, approach to gastrointestinal (GI) infections, chronic diarrhea, non-IBD intestinal disorders, nutritional therapy, and malabsorption. Regional small meetings were identified by the majority $(61 \%)$ of respondents as the most useful format for accredited learning activities.

\section{INTRODUCTION}

The purpose of the CAG needs assessment was to provide guidance to the Executive and the CAG Education Affairs committee on areas of greatest educational need. Conducting a needs assessment is a requirement for accreditation of educational events in accordance with the Royal College of Physicians and Surgeons of Canada.

\section{METHODS}

The members of Education Affairs include Drs Collin Barker, Janice Barkey, Kelly Burak, Maria Cino, Mary-Anne Cooper, Dana Farina, Jamie Gregor, Supriya Joshi, Gabor Kandel, Remo Panaccione, Craig Render, Jeffrey Stal, Connie Switzer and Kevin Waschke; and trainee members Andrea Faris and Jennifer Williams. A subgroup of the committee designed the needs assessment survey, which was a slightly modified version of that used in 2006.

The needs assessment was posted online on the CAG Web site and members were requested by e-mail to complete the simple 'tick box' survey. Data were compiled and analyzed at the CAG National Office.

The survey included three sections. The first collected basic demographic information, the second questioned members on their interest in topics for educational events and the third section explored desired formats for accredited learning activities.

Respondents were asked to rate their interest in 51 potential topics for educational events using a scale of one (no interest) to seven (extremely interested). For activities to earn Maintenance of Certification credits, respondents were to select the two learning formats that they found to be most useful.

\section{RESULTS}

A generic e-mail request to CAG members in March and April resulted in approximately 60 individuals completing the needs assessment. A subsequent, personalized e-mail request to members succeeded in generating another 168 responses for a total of 228 completed surveys, representing $21 \%$ of the solicited membership.

\section{Demographics}

All respondents were CAG members and $72 \%$ were men. Regarding education, $66 \%$ were MDs or equivalent, $7 \%$ were $\mathrm{MD} / \mathrm{PhDs}, 17 \%$ were $\mathrm{PhDs}$ and $10 \%$ held another degree. Most respondents were affiliated with a teaching hospital $(84 \%)$, rather than being community-based, with $(2 \%)$ or without (2\%) hospital privileges, although $12 \%$ left this question blank.

Most replies were from individuals in Ontario (36\%), followed by Alberta (28\%), Quebec (14\%) and British Columbia $(8 \%)$, with responses distributed roughly in proportion to provincial population.

Respondents' specialty was identified as adult gastroenterology by $50 \%$ of respondents, pediatric gastroenterology by $12 \%$, hepatology by $2 \%$ and surgery by $2 \%$. Basic and clinical scientists made up $20 \%$ and $1 \%$, respectively, of respondents. Residents and fellows accounted for 6\%, and 'other' roles accounted for $7 \%$.

Regarding where respondents spend their time, $43 \%$ identified clinical practice as their primary focus and 26\% noted basic research (more than $50 \%$ of time on research). Clinicianteachers (50\% or less of time teaching) and clinical researchers (50\% or less of time on research) formed the next biggest group, at $10 \%$ and $9 \%$, respectively. Less commonly, individuals were involved in clinical research (more than $50 \%$ of the time) (4\%), administration (more than $50 \%$ of the time) $3 \%$ ) or 'other' duties (4\%).

\begin{tabular}{|c|c|c|}
\hline \multicolumn{3}{|c|}{ The CAG is proud to acknowledge its Benefactor Corporate Sponsors: } \\
\hline Abbott Laboratories Ltd & AstraZeneca Canada Inc & Janssen-Ortho Inc \\
\hline Nycomed Canada Inc (formerly & Olympus Canada Inc & Canada Inc \\
\hline Pfizer Canada In & Procter \& Gamble Pharmaceuticals & Canada Inc \\
\hline
\end{tabular}




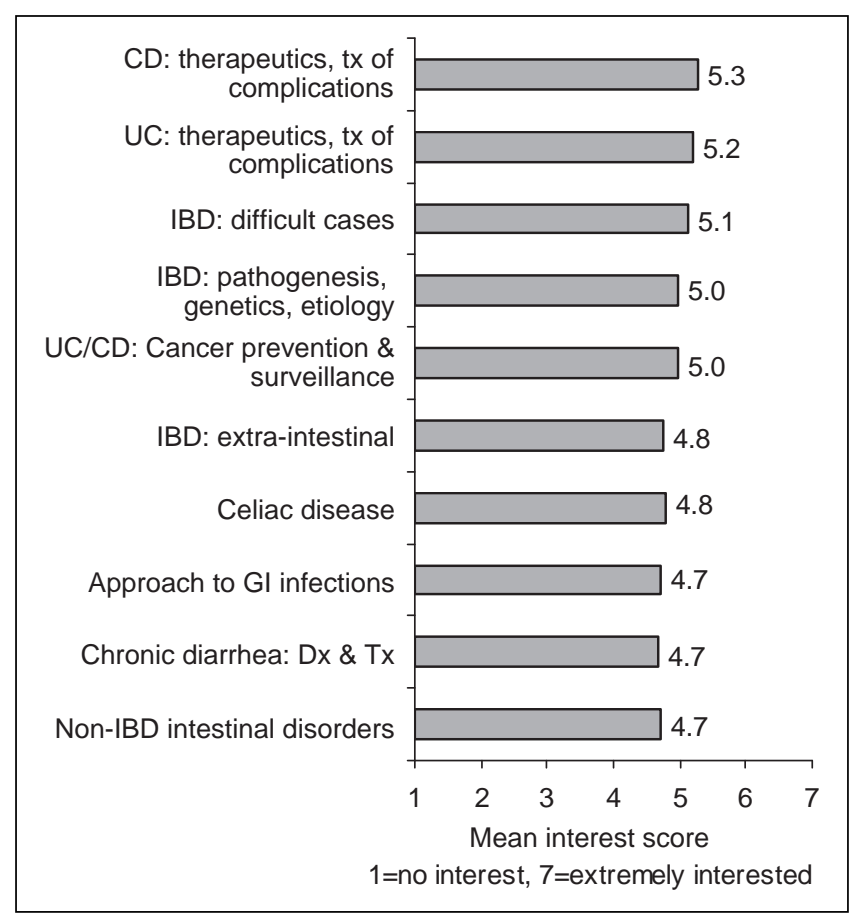

Figure 1) Scientific educational topics scoring 4.7 or higher on mean interest score. CD Crohn's disease; Dx Diagnosis; GI Gastrointestinal; IBD Inflammatory bowel disease; Tx Treatment; UC Ulcerative colitis

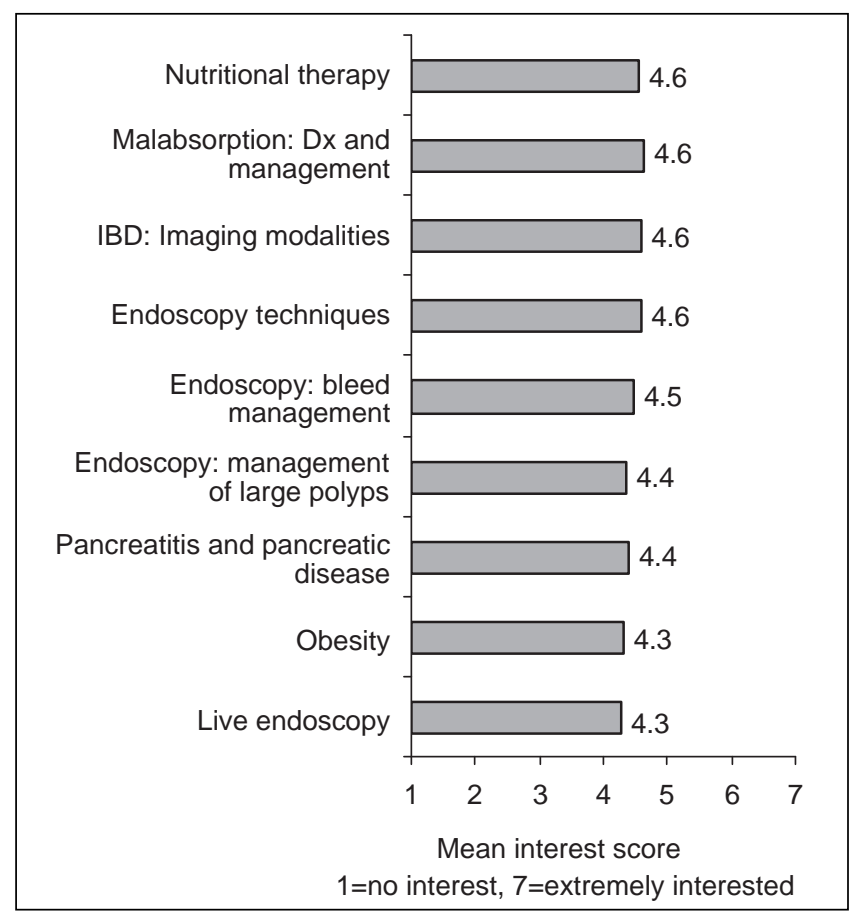

Figure 2) Scientific educational topics scoring 4.3 to 4.6 on mean interest score. Dx Diagnosis; IBD Inflammatory bowel disease

Educational topics

The mean interest scores for the 44 scientific educational topics are shown in Figures 1 to 5. Consistent with past years, inflammatory bowel disease topics received the highest ratings: Crohn's disease (CD) therapeutics/treatment of complications, fistulas, etc (mean 5.3); ulcerative

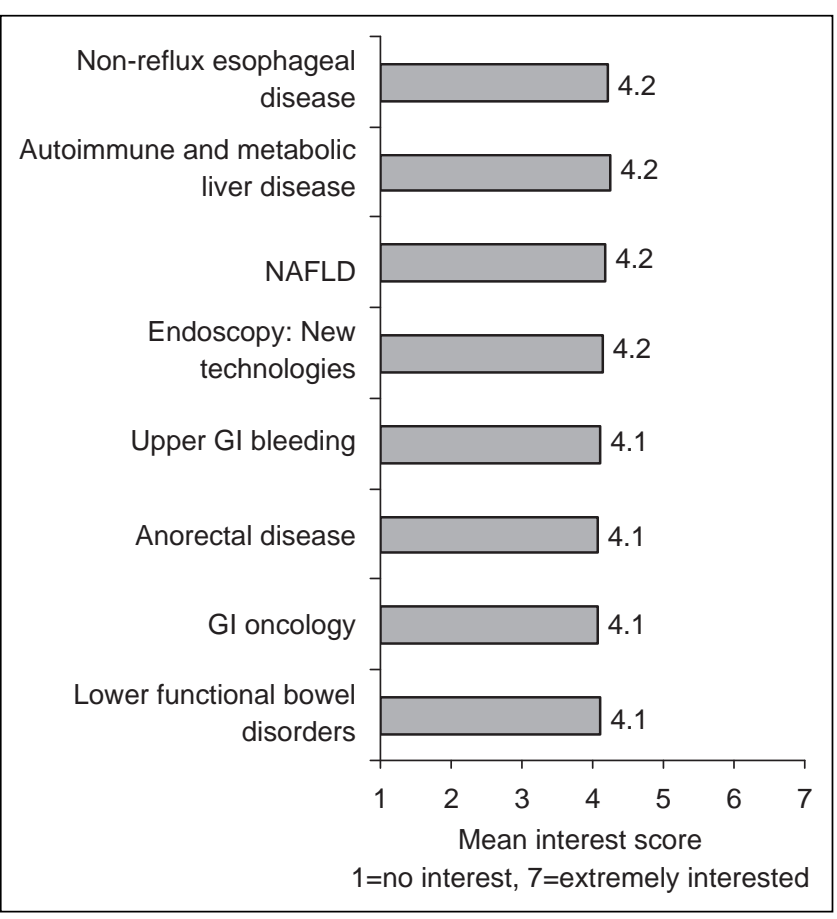

Figure 3) Scientific educational topics scoring 4.1 to 4.2 on mean interest score. GI Gastrointestinal; NAFLD Nonalcoholic fatty liver disease

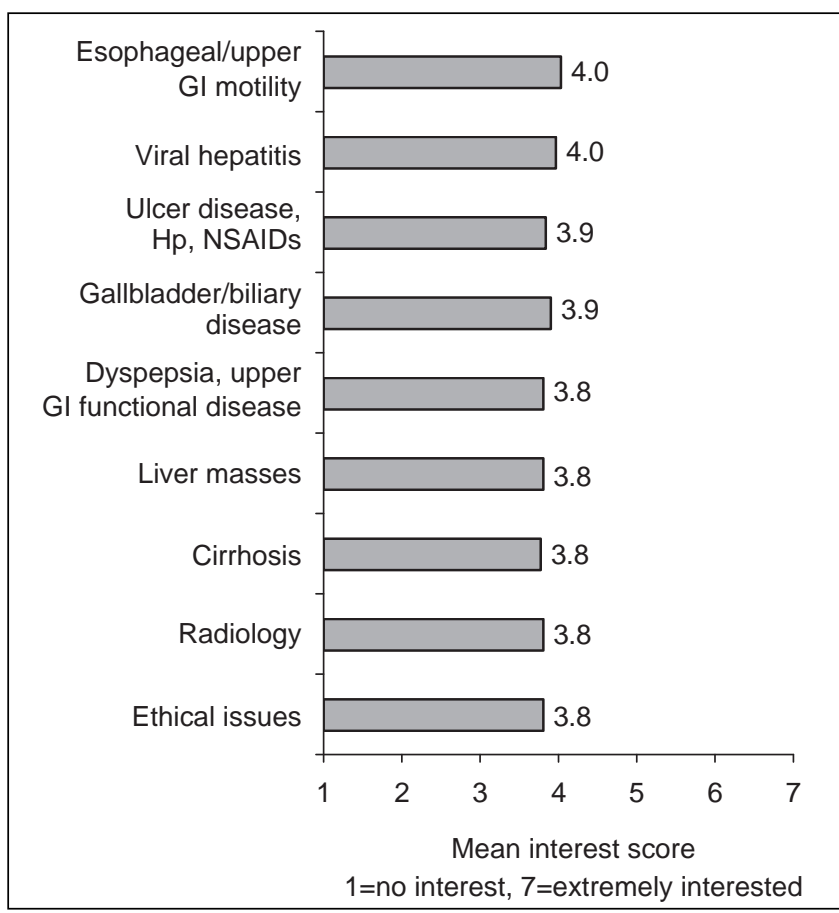

Figure 4) Scientific educational topics scoring 3.8 to 4.0 on mean interest score. GI Gastrointestinal; Hp Helicobacter pylori; NSAIDs Nonsteroidal anti-iflammatory drugs

colitis (UC) therapeutics/treatment of complications (mean 5.2); difficult cases in IBD (mean 5.1); IBD pathogenesis, genetics, etiology (mean 5.0); UC/CD: cancer prevention and cancer surveillance (mean 5.0); and IBD: extra-intestinal manifestations (mean 4.8). Celiac disease (mean 4.8) and nutritional therapy (mean 4.6) were also 


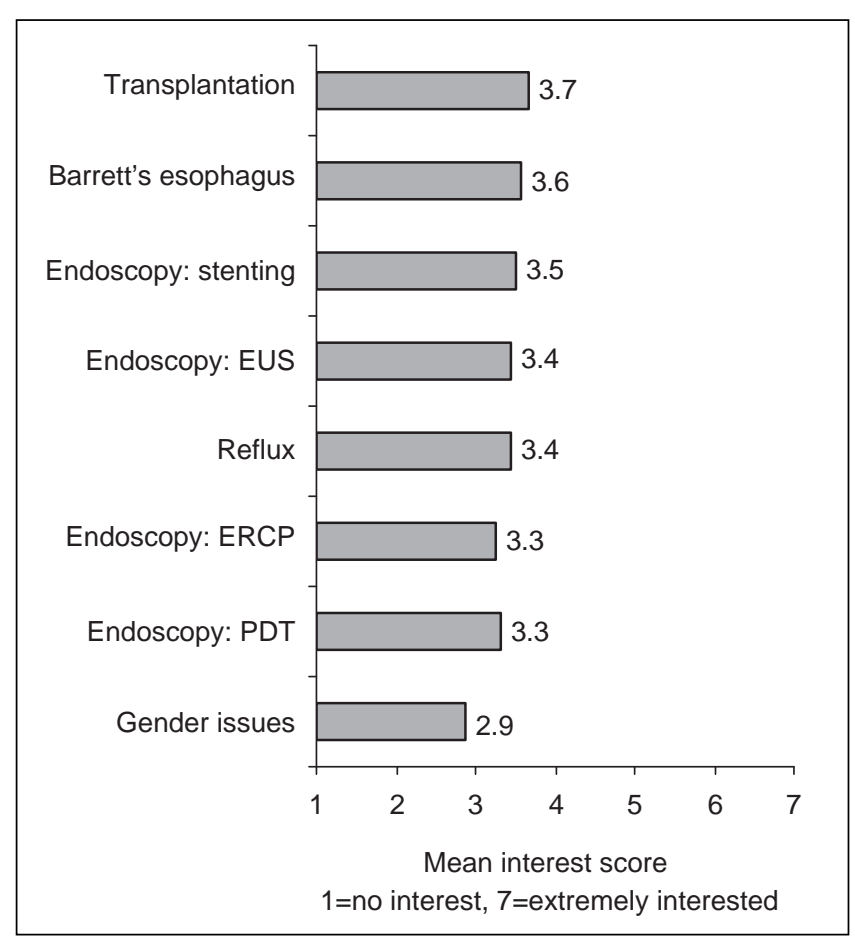

Figure 5) Scientific educational topics scoring less than 3.8 on mean interest score. ERCP Endoscopic retrograde cholangiopancreatography; EUS Endoscopic ultrasound; PDT Photodynamic therapy

in demand as per past years' surveys. Several new topics introduced for 2007 scored highly, presenting novel options for future educational events: approach to GI infections (Clostridium difficile and other pathogens) (mean 4.7); chronic diarrhea diagnosis and management (mean 4.7); non-IBD intestinal disorders (microscopic colitis, etc) (mean 4.7); and malabsorption diagnosis and management (mean 4.6).

Responses for nonscientific educational event topics are given in Figure 6. The highest scores of 4.2 for teaching theory and techniques, and 4.1 for gastroenterology and the internet were still lower than the top-scoring scientific topics.

\section{Learning formats}

Regarding the two most desired formats for accredited learning activities, $61 \%$ identified regional small meetings on a specific topic or small group of topics. Less commonly selected formats were web-based interactive learning $(49 \%)$, visiting professor rounds (39\%) and distributed CD-ROM materials (35\%).

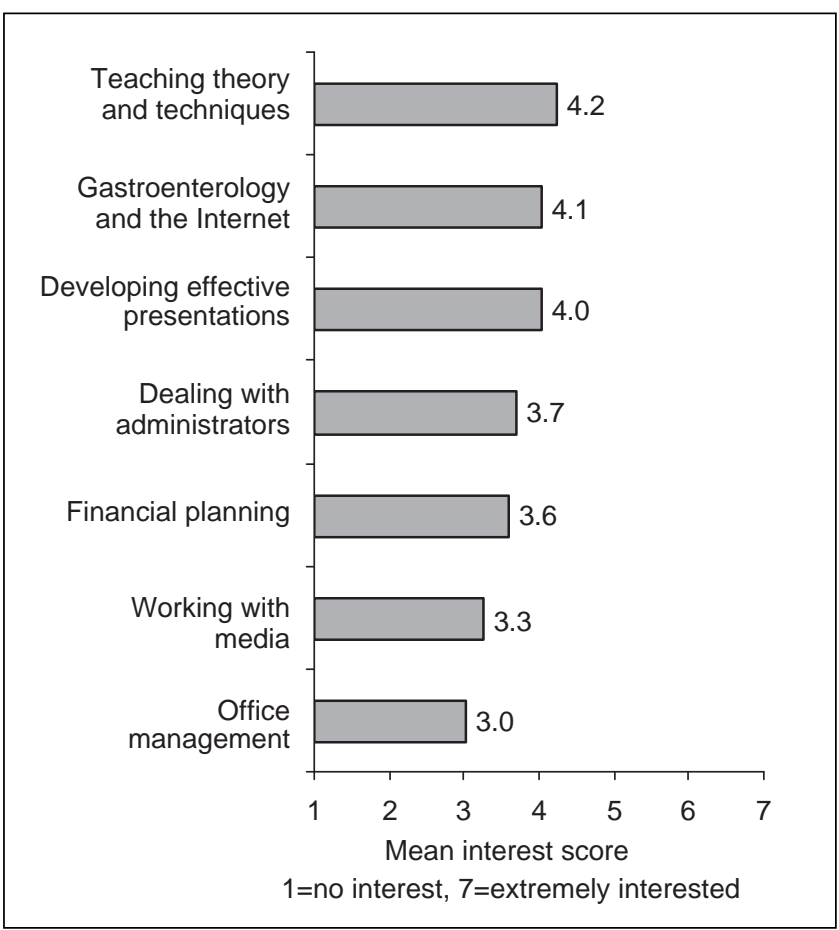

Figure 6) Mean interest score for nonscientific topics

\section{DISCUSSION}

Twenty-one per cent ( $n=228)$ of the solicited membership participated in the full survey. Although the initial response was poor, members are to be commended for answering a second personalized request for input. An ongoing priority for Education Affairs is to develop innovative and easy assessment tools to encourage greater participation by members to accurately reflect their educational needs.

IBD remains the highest priority of respondents despite yearly Canadian Digestive Disease Week (CDDW) sessions in this area since 2002. Apart from IBD, celiac disease and nutritional therapy were again popular, as per previous years. Of interest from this year's survey was the introduction of new topics that scored highly; these included approach to GI infections, diagnosis and management of chronic diarrhea, non-IBD intestinal disorders, and malabsorption diagnosis and management. These findings, along with evaluations of CDDW 2007 and identification of unrecognized educational needs, have formed the basis of the 2008 CDDW program. 


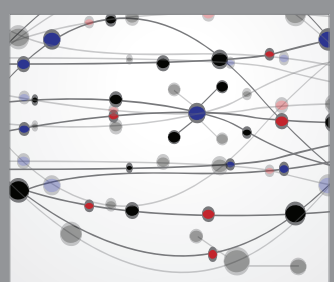

The Scientific World Journal
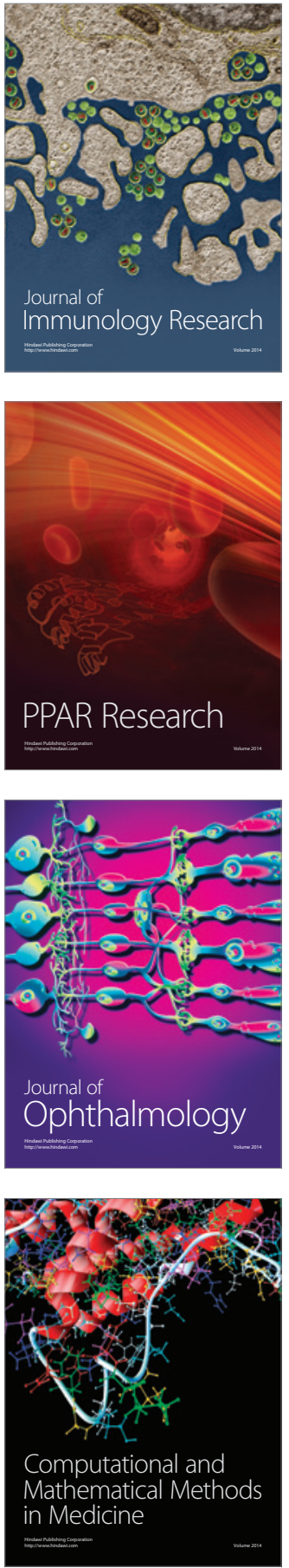

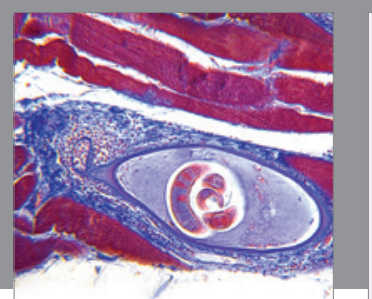

Gastroenterology Research and Practice

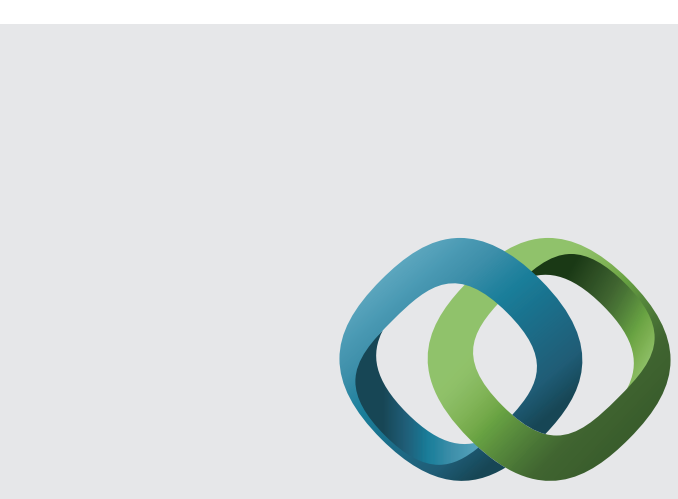

\section{Hindawi}

Submit your manuscripts at

http://www.hindawi.com
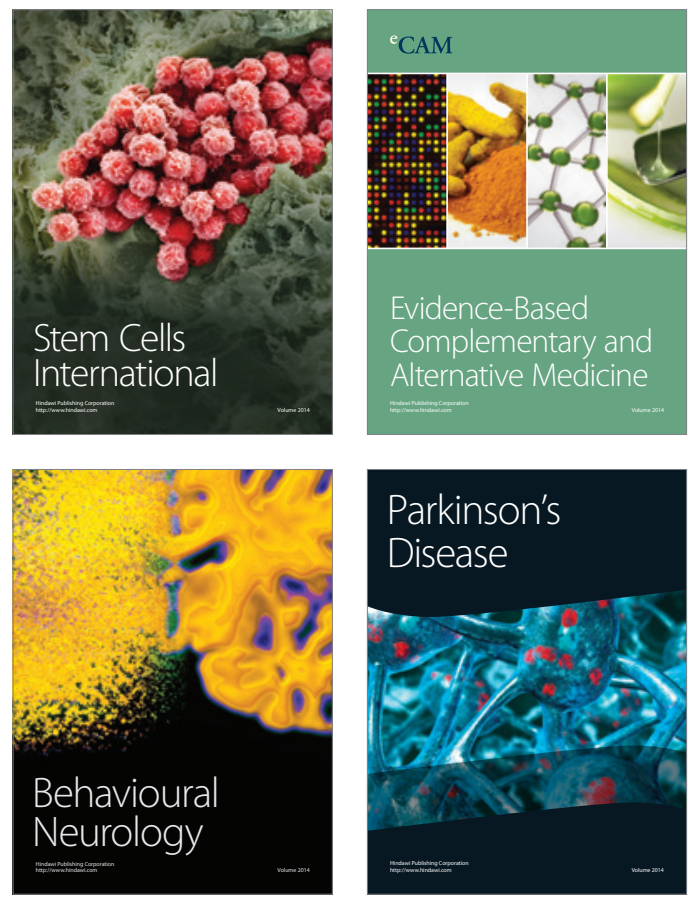
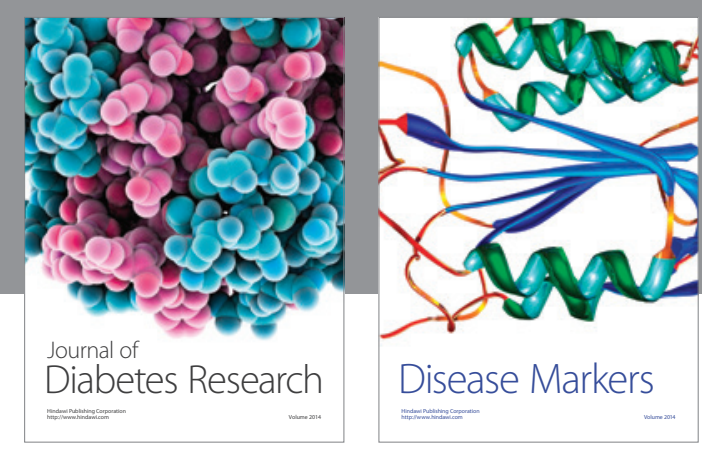

Disease Markers
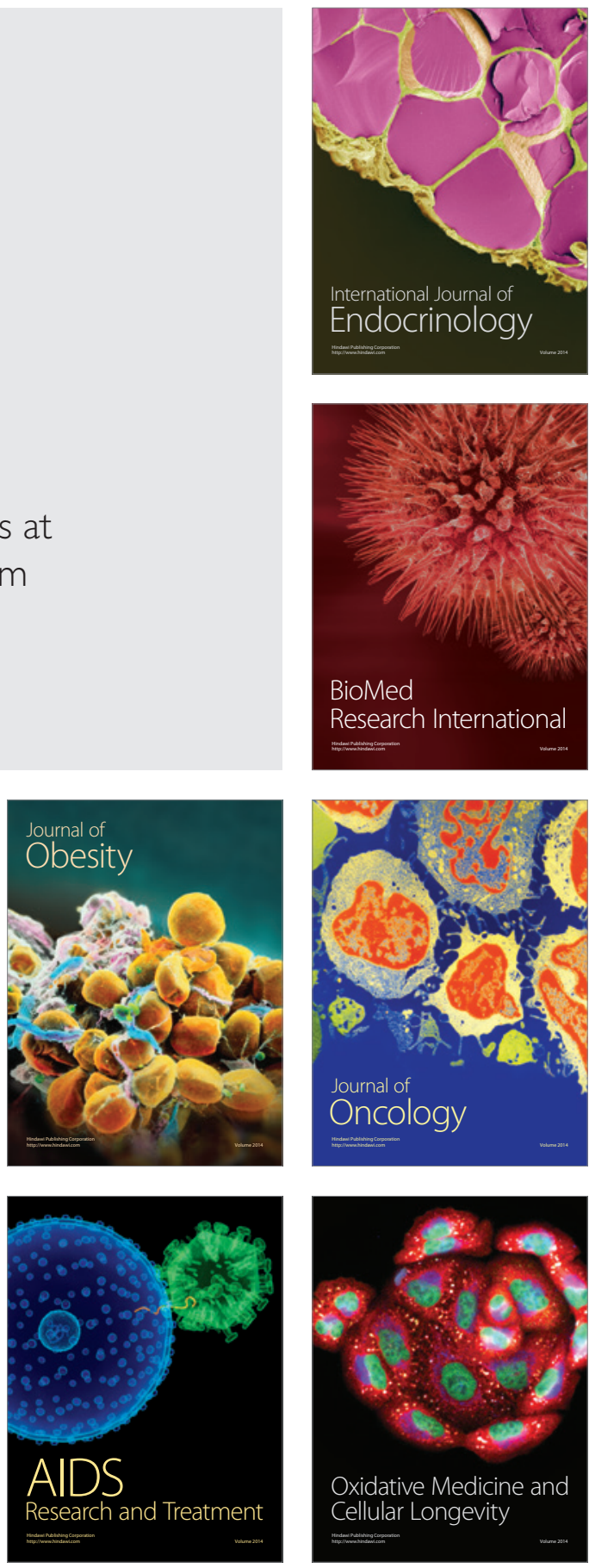